\title{
УЛЬТРАЗВУКОВАЯ ДОППЛЕРОГРАФИЯ ХРОНИЧЕСКОЙ ВЕНОЗНОЙ НЕДОСТАТОЧНОСТИ НИЖНИХ КОНЕЧНОСТЕЙ
}

\author{
๑Ш. А. Юсупов, Г. М. Мардыева, Н. Р. Аскарова \\ Самаркандский государственный медицинский институт, Самарканд, Узбекистан
}

РЕзЮМЕ. Цель исследования - изучить возможности ультразвуковой допплерографии в диагностике хронической венозной недостаточности (ХВН) нижних конечностей.

Материал и методы. Проведено обследование 176 пациентов с ХВН. Использован метод цветовой допплерографии.

Результаты и обсуждение. ХВН у обследованных пациентов проявлялась разнообразной клинической симптоматикой. Для оценки тонуса венозной стенки определяли индекс эластичности (ИЭ) общей бедренной и подколенной вен, для определения «нормальности» анатомического строения большой подкожной вены на бедре определяли индекс гипоплазии. Характеризовав гемодинамическую значимость, разделили всех обследованных больных по степеням тяжести на три группы. В первой группе при проведении проб на клапанах в сафенофеморальном соустье ретроградный кровоток не фиксировался, что подтверждало отсутствие клапанной недостаточности. Значение ИЭ не превышало $(1,37 \pm 0,09)$. Во второй группе регистрировали ретроградный ток крови длительностью не более 2 секунд, свидетельствующий о гемодинамически незначимой недостаточности. ЗначениеИЭбыловыше 1,37. Упациентовтретьей группыприпроведениипробнаклапанахв сафенофеморальном соустье регистрировался ретроградный ток крови, что позволило выявить гемодинамически значимую клапанную недостаточность, при которой показана хирургическая коррекция. Средние показатели ИЭ глубоких вен превышали нормальное значение и составляли для общей бедренной вены $(1,7 \pm 0,042)$, для подколенной вены- $(1,6 \pm 0,028)$.

Выводы. Ультразвуковая допплерография позволила выявить клапанную недостаточность различных отделов венозного русла нижних конечностей и сделать заключение о степени нарушения венозного оттока вен нижних конечностей. Изучение с помощью ультразвуковой допплерографии тонико-эластических свойств венозной стенки является одним из важных моментов в диагностике состояния венозной системы нижних конечностей и имеет важное практическое значение. Развитие XВН - процесс, протяженный во времени, то есть при условии обнаружения и лечения заболевания на ранних стадиях можно реально сократить количество заболевших или пролонгировать во времени развитие тяжелых форм болезни.

КЛЮчЕВЫЕ СЛОВА: ультразвуковая допплерография; хроническая венозная недостаточность.

Введение. Хроническая венозная недостаточность (XBH) нижних конечностей в настоящее время является самой распространенной патологией сосудистой системы человека. По данным зарубежных флебологов, от 15 до 40 \% населения развитых стран страдает теми или иными заболеваниями венозной системы, причем у $25 \%$ пациентов выявляются признаки ХВН. Столь высокая распространенность позволяет смело называть ХВН «болезнью цивилизации». Более того, если раньше заболевание относили к проблемам лиц старшей возрастной группы (более 50 лет), то сейчас у 10-15 \% школьников в возрасте 12-13 лет выявляют первые признаки венозного рефлюкса [2, 4].

ХВН нижних конечностей - синдром, характеризующийся нарушениями венозного оттока, которые приводят к дезорганизации регионарной системы микроциркуляции. Она возникает в результате структурных или функциональных расстройств венозной системы, связанных с нарушением венозного оттока из нижних конечностей и проявляется рядом клинических синдромов и симптомов, выраженность которых зависит от стадии заболевания $[2,5]$.
В качестве важнейшей проблемы, оказывающей негативное влияние на развитие и прогрессирование ХВН, следует отметить позднее обращение пациентов за врачебной помощью. Значительная часть больных полагает, что симптомы хронической венозной недостаточности являются нормальным следствием утомления и продолжительных статических нагрузок. Некоторые недооценивают тяжесть патологии и не отдают себе отчет в том, к каким осложнениям может привести ХВН. Актуальность выявления ранних (доклинических) стадий заболевания, когда возможно проведение адекватных профилактических мероприятий, очевидна $[1,3]$.

Цель исследования - изучить возможности ультразвуковой допплерографии в диагностике ХВН нижних конечностей.

Материал и методы исследования. Проведено обследование 176 пациентов с ХВН в возрасте от 15 до 70 лет, из них женщины составили 61 \%, мужчины - 39 \%. Диагноз устанавливали на основании анамнестических данных, жалоб пациента, результатов объективного и инструментального исследований. Использован метод цветовой допплерографии. Допплерографию прово- 
Огляди літератури, оригінальні дослідження, погляд на проблему

дили в положении больного лежа и стоя, а также с нагрузочными пробами, на ультразвуковом сканере MINDRAYDC-3 с датчиком линейного формата, рабочей частотой 7,5 МГц. Цветовое допплеровское картирование кровотока - двухмерное изображение биологических структур, в котором скорость движения отдельных элементов отображается с помощью цвета различных оттенков.

Результаты и обсуждение. Симптомы начальных проявлений ХВН были многообразны и неспецифичны. На ранних стадиях проявлялся один или несколько симптомов. Варикозно расширенные вены в начальной стадии хронической венозной недостаточности отмечались не у всех обследованных. На начальных стадиях, даже при отсутствии варикозной трансформации, внимательный осмотр нижних конечностей позволил обнаружить усиление подкожного венозного рисунка, свидетельствующее о снижении тонуса венозной стенки.

ХВН у обследованных пациентов проявлялся разнообразной клинической симптоматикой. Отбор пациентов производили согласно следующим критериям: жалобы на боль, зуд, ощущение тяжести и усталость в ногах в конце дня (18,2%), отечность нижних конечностей (17,05 \%), судороги икроножных мышц ночью (7,95 \%), регрессирующие после ночного отдыха, наличие телеангиэктазий $(11,93$ \%) и ретикулярного варикоза (8,52 \%), т. е. разновидность простого варикозного расширения вен, при котором наблюдается расширение тонких внутрикожных вен. У 32 больных выявлена прогрессирующая ХВН нижних конечностей, которая характеризовалась появлением и развитием синдрома «беспокойных ног» и сопровождалась болью, судорогами, зудом, парестезиями.

Клапанная недостаточность различных отделов венозного русла нижних конечностей, приводящая к появлению патологического ретроградного потока крови - основного фактора повреждения микроциркуляторного русла, подтверждалась обследованиями венозной системы нижних конечностей с привлечением ультразвуковых методов.

Ультразвуковая допплерография - важный метод, способствующий диагностике ХВН на ранних стадиях, позволяющий сделать заключение о степени нарушения венозного оттока вен нижних конечностей. Допплеровское исследование выполняли с целью уточнения причины заболевания вен нижних конечностей; оценки состояния глубоких вен (проходимость и состоятельность клапанов); обнаружения рефлюкса через сафенофеморальное и сафеноподколенное соустья; определения состояния клапанного аппарата стволов большой и малой подкожных вен; выявления наличия и локализации несостоятельных перфорантных вен.

Для оценки тонуса венозной стенки определяли индекс эластичности (ИЭ) общей бедренной и подколенной вен. ИЭ вычисляли как отношение диаметра сосуда в вертикальном положении к диаметру в горизонтальном положении пациента. В контрольной группе значение ИЭ не превышало $(1,37 \pm 0,09)$, что соответствует физиологической эластичности венозной стенки.

Для определения «нормальности» анатомического строения большой подкожной вены на бедре, как при наличии ретроградного сброса, так и при его отсутствии, в клиностазе определяется отношение диаметра большой подкожной вены в нижней трети бедра к диаметру в верхней трети (индекс гипоплазии большой подкожной вены на бедре). В контрольной группе значение индекса гипоплазии не превышало 1.

Для оценки не только проходимости глубоких вен, но и состоятельности клапанов глубоких, подкожных и перфорантных вен, использовали компрессионные пробы, гемодинамической основой которых является искусственное повышение давления в просвете вены проксимальнее клапана, что в норме ведет к смыканию створок клапана и прекращению кровотока. Для оценки функциональной состоятельности клапанного аппарата использовали пробу Вальсальвы, заключающуюся в выполнении пациентом глубокого вдоха с одновременным натуживанием и надутием живота. В зависимости от наличия или отсутствия рефлюкса на клапанах можно говорить о состоятельности последних, а также о наличии венозной недостаточности.

Характеризовав гемодинамическую значимость, учитывая соответствующие признаки, разделили всех обследованных больных по степени тяжести на следующие группы. Первую группу составили 26 больных (14,77\%), у которых при проведении проб на клапанах в сафенофеморальном соустье ретроградный кровоток не фиксировался, что подтверждало отсутствие клапанной недостаточности. Значение ИЭ не превышало $(1,37 \pm 0,09)$, что соответствует физиологической эластичности венозной стенки. У 116 больных (65,91\%), составивших вторую группу, допплерография регистрировала ретроградный ток крови длительностью не более 2 секунд, свидетельствующий о гемодинамически незначимой недостаточности. Нарушений проходимости венозных сосудов нижних конечностей на ультразвуковой допплерограмме не было. Значение ИЭ было выше 1,37. И, наконец, в третьей группе, в которую вошли 34 пациента (19,3%), при проведении 
Огляди літератури, оригінальні дослідження, погляд на проблему

проб на клапанах в сафенофеморальном соустье регистрировался ретроградный ток крови. Это позволило выявить гемодинамически значимую клапанную недостаточность, при которой показана хирургическая коррекция. Средние показатели ИЭ глубоких вен превышали нормальное значение и составляли для общей бедренной вены $(1,7 \pm 0,042) ;$ для подколенной вены - $(1,6 \pm 0,028)$.

Все изложенное выше свидетельствует о необходимости проведения эффективной диагностики ХВН на самых ранних стадиях развития патологии. Хронический прогрессирующий характер заболевания диктует необходимость ранней диагностики и динамического наблюдения за пациентом.

Выводы. 1. Ультразвуковая допплерография позволяет выявить клапанную недостаточность различных отделов венозного русла нижних ко- нечностей, приводящую к появлению патологического ретроградного потока крови.

Изучение с помощью ультразвуковой допплерографии тонико-эластических свойств венозной стенки является одним из важных моментов в диагностике состояния венозной системы нижних конечностей и имеет важное практическое значение.

Ультразвуковая допплерография позволяет сделать заключение о степени нарушения венозного оттока вен нижних конечностей, способствуя диагностике ХВН на ранних стадиях.

Перспективы дальнейших исследований. Полученные результаты могут служить для диагностики ХВН на ранних стадиях, что поможет реально сократить количество заболевших или пролонгировать во времени развитие тяжелых форм болезни.

\section{ЛИТЕРАТУРА}

1. Золотухин И. А. Дифференциальная диагностика отеков нижних конечностей / И. А. Золотухин // Консилиум медикум. - 2004. - Т. 6, № 5. - С. 11-14.

2. Ивашкевич В. М. Ранняя диагностика, профилактика и лечение хронической венозной недостаточности нижних конечностей / В. М. Ивашкевич // Медицинские новости. - 2015. - № 2. - С. 56-59.

3. Климова Е. А. Хроническая венозная недостаточность и методы ее лечения [Електронний ресурс] / Е. А. Климова // Русский медицинский журнал. - 2009.

\section{REFERENCES}

1. Zolotuxin, I.A. (2004). Differenetsialnaya diagnostika otekov nizhnikh konechnostey [Differential diagnosis of edema of the lower limbs]. Konsilium medikum - Consilium Medicum, 6 (5), 11-14 [in Russia].

2. Ivashkevich, V.M. (2015). Rannyaya diagnostika, profilaktika i lechenie khronicheskoy venoznoy nedostatochnosti nizhnikh konechnostey [Early diagnosis, prevention and treatment of chronic venous insufficiency of the lower extremities]. Meditsinskie novosti - Journal of Medical News, 2, 56-59 [in Russian].

3. Klimova, E.A. (2009). Khronicheskaya venoznaya nedostatochnost i metody ee lecheniya [Chronic venous
- № 12. - С. 828. - Режим доступу: sites/default/files/ mmi2009_12_828.pdf.

4. Осипов Д. В. Диагностика хронической венозной недостаточности нижних конечностей у подростков: автореф. дис. на соискание ученой степени канд. мед. наук :14.00.09 / Осипов Дмитрий Владиславович. - Москва, 2007. - 20 c.

5. Nicolaides A. N. Investigation of Chronic Venous Insufficiency. A Consensus Statement / A. N. Nicolaides // Circulation. - 2000. - Vol. 102. - P. 126. insufficiency and methods of its treatment]. Russkiy meditsinskiy zhurnal - Russian Medical Journal, 12, 828. Retrieved from: http://www.rmj.ru/articles/khirurgiya/ sites/default/files/ mmi2009_12_828.pdf. [in Russia].

4. Osipov, D.V. (2007). Diagnostika khronicheskoy venoznoy nedostatochnosti nizhnikh konechnostey u podrostkov [Diagnosis of chronic venous insufficiency of the lower extremities in adolescents]. Extended abstract of candidate's thesis. Moscow [in Russian].

5. Nicolaides, A.N. (2000). Investigation of chronic venous insufficiency. A consensus statement. Circulation, 102, 126. 


\author{
@Sh. A. Yusupov, G. M. Mardyeva, N. R. Askarova \\ Samarkand State Medical Institute, Samarkand, Uzbekistan
}

SUMMARY. The aim was to study the possibilities of ultrasonic dopplerography in the diagnosis of chronic venous insufficiency (CVI) of the lower limbs.

Materials and Methods. A total of 176 patients with CVI were examined. The method of color dopplerography was used.

Results and Discussion. CVI in the examined patients manifested a variety of clinical symptoms. To assess the tone of the venous wall, the elasticity index (IE) of the total femoral and popliteal veins was determined, to determine the "normality" of the anatomical structure of the large saphenous vein on the thigh, the hypoplasia index was determined. Characterizing the hemodynamic significance, all the examined patients were divided into three groups according to the degrees of severity. In the first group, when samples were performed on the valves in the saphenofemoral anastomosis, retrograde blood flow was not recorded, which confirmed the absence of valvular insufficiency. The value of IE did not exceed $1.37 \pm 0.09$. The second group recorded a retrograde blood flow lasting no more than 2 seconds, indicating a hemodynamically insignificant insufficiency. The IE value was higher than 1.37. Patients of the third group had a retrograde blood flow during the sampling of valves in the saphenofemoral anastomosis, which made it possible to reveal a hemodynamically significant valvular insufficiency, in which surgical correction was shown. The mean indices of deep vein IE exceeded the normal value and amounted to $1.7 \pm 0.042$ for the general femoral vein, $1.6 \pm 0.02$ for the popliteal vein.

Conclusions. Ultrasonic dopplerography made it possible to reveal the valve insufficiency of various sections of the venous bed of the lower extremities and to draw a conclusion about the degree of disturbance of venous outflow of the veins of the lower extremities. The study of the tonic-elastic properties of the venous wall with the help of ultrasound dopplerography is one of the important moments in the diagnosis of the state of the venous system of the lower extremities and is of great practical importance. Development of CVI is a long process, that is, under condition of detection and treatment of the disease in the early stages, it is possible to actually reduce the number of cases or prolong the development of severe forms of the disease in time.

KEY WORDS: ultrasound dopplerography; chronic venous insufficiency.

\title{
УЛЬТРАЗВУКОВА ДОПЛЕРОГРАФІЯ ХРОНІЧНОЇ ВЕНОЗНОї НЕДОСТАТНОСТІ НИЖНІХ КІНЦІBOK
}

\author{
○Ш. А. Юсупов, Г. М. Мардиева, Н. Р. Аскарова \\ Самаркандський державний медичний інститут, Самарканд, узбекистан
}

РЕзюМЕ. Мета дослідження - вивчити можливості ультразвукової доплерографії в діагностиці хронічної венозної недостатності (ХВН) нижніх кінцівок.

Матеріал та методи. Проведено обстеження 176 пацієнтів з ХВН. Використаний метод кольорової доплерографії.

Результати. ХВН у обстежених пацієнтів проявлялася різноманітною клінічною симптоматикою. Для оцінки тонусу венозної стінки визначали індекс еластичності (IE) загальної стегнової і підколінної вен, для визначення «нормальності» анатомічної будови великої підшкірної вени на стегні визначали індекс гіпоплазії. Характеризувавши гемодинамічну значимість, поділили всіх обстежених хворих за ступенями тяжкості на три групи. У першій групі при проведенні проб на клапанах в сафенофеморальному співусті ретроградний кровотік не фіксували, що підтверджувало відсутність клапанної недостатності. Значення IE не перевищувало $(1,37 \pm 0,09)$. У другій групі реєстрували ретроградний потік крові тривалістю не більше 2 секунд, що свідчить про гемодинамічно незначущу недостатність. Значення IE було вище $1,37$. У пацієнтів третьої групи при проведенні проб на клапанах в сафенофеморальному співусті реєструвався ретроградний потік крові, що дозволило виявити гемодинамічно значиму клапанну недостатність, при якій показана хірургічна корекція. Середні показники IE глибоких вен перевищували нормальне значення і становили для загальної стегнової вени $(1,7 \pm 0,042)$, для підколінної вени - $(1,6 \pm 0,028)$.

Висновки. Ультразвукова доплерографія дозволила виявити клапанну недостатність різних відділів венозного русла нижніх кінцівок і зробити висновок про ступінь порушення венозного відтоку вен нижніх кінцівок. Вивчення за допомогою ультразвукової доплерографії тоніко-еластичних властивостей венозної стінки $є$ одним з важливих моментів в діагностиці стану венозної системи нижніх кінцівок і має важливе практичне значення. Розвиток ХВН - процес, тривалий за часом, тобто за умови виявлення і лікування захворювання на ранніх стадіях можна реально скоротити кількість хворих або пролонгувати в часі розвиток тяжких форм хвороби.

КлючОВІ СлОВА: ультразвукова доплерографія; хронічна венозна недостатність. 